\title{
Optimal decision problem in a three-level closed-loop supply chain with risk-averse players under demand uncertainty
}

\author{
Safoura Famil Alamdar ${ }^{\mathrm{a}}$, Masoud Rabbani ${ }^{\mathrm{a}^{*}}$ and Jafar Heydari ${ }^{\mathrm{a}}$
}

\begin{tabular}{|c|c|}
\hline CHRON I C LE & A B S T RACT \\
\hline $\begin{array}{l}\text { Article history: } \\
\text { Received May 16, } 2018 \\
\text { Accepted July 16 } 2018 \\
\text { Available online } \\
\text { July } 172018 \\
\text { Keywords: } \\
\text { Closed-loop supply chains } \\
\text { Risk-averse } \\
\text { Collection effort } \\
\text { Sales effort } \\
\text { Game theory } \\
\text { Coordination contract }\end{array}$ & $\begin{array}{l}\text { In this paper, a stochastic model of a closed-loop supply chain (CLSC) with one risk-averse } \\
\text { manufacturer, one risk-averse retailer and one risk-averse third party is developed. To analyze } \\
\text { how the members make decisions about wholesale price, collection rate, retail price and sales } \\
\text { effort under different decision-making structures, the optimal decision problem under } \\
\text { uncertain price and sales effort-dependent demand is studied through development of four } \\
\text { game theoretical models. The equilibrium results between various models are compared and } \\
\text { the optimal decisions from each member's perspective are investigated. According to the } \\
\text { results, the third party-led model has better performance than manufacturer-led model. The } \\
\text { cooperation mode of manufacturer and retailer is beneficial for the whole chain and customers } \\
\text { and the cooperation mode of manufacturer and third party is the most effective model to collect } \\
\text { the used-product. Finally, to increase the performance of decentralized CLSC compared with } \\
\text { the centralized CLSC, a coordination contract is developed. The results indicate that this } \\
\text { contract is advantageous for the members of CLSC, the customers, and the environmental } \\
\text { issues. }\end{array}$ \\
\hline
\end{tabular}

(C) 2018 by the authors; licensee Growing Science, Canada

\section{Introduction}

Closed loop supply chain (CLSC) is defined as "from the perspective of the product total life cycle, integrating the traditional forward supply chain activities and a set of additional activities of reverse supply chain, i.e., designing, planning and controlling in the whole process from the acquisition and production to redistribution, in order to recapture additional values" (Fleischmann et al., 1997; Guide $\&$ Wassenhove, 2006). Due to increased environmental consciousness, environmental concerns and strict environmental laws, CLSC management has become attractive for both business and academic research throughout this decade (Prahinski \& Kocabasoglu, 2006). CLSC has become an element that companies must consider in decision-making processes concerning the design and development of their supply chains (Rubio \& Corominas, 2008). For instance, Xerox is a leader in remanufacturing the highvalue, end-of-lease copiers for producing the new copiers. Also, Hewlett Packard reuses the used peripherals and computers. Similar activities are undertaken by Canon for print and copy cartridges (Savaskan \& Van Wassenhove, 2006). A simple CLSC consists of three types of members: the manufacturer/remanufacturer, the retailer, and the third-party (collector) (Savaskan et al., 2004).

* Corresponding author Tel.: +98 218 8021067; fax: +98 2188013102 E-mail address: mrabani@ut.ac.ir (M. Rabbani) 
Usually, manufacturers such as Toyota and GM have a leadership role and the retailers are the followers (Cachon, 2003). In recent years, giant collectors such as SIMS Metal Management, AER Worldwide and IBM's Global Asset Recovery Services take the market power and act as the channel leader in the CLSC (Karakayali et al., 2007).

Also, there are different coalition structures in CLSCs in real life. For instance, the "big three" auto manufacturers in the United States (i.e., GM, Chrysler, Ford) have established a long-term cooperative partnership with recyclers. Moreover, in some situations, the manufacturer and the retailer such as P\&G and Wal-Mart can establish a good cooperative relationship (Zu-Jun et al., 2016). So, analyzing the decisions of participants under various power structures and different cooperative behaviors has been increasingly noticed in CLSC management. However, in many cases, the supply chain members, in addition to increasing their profits, seek to reduce their risk. There have been several studies carried out on forward supply chain management with risk-averse players (Xiao \& Yang, 2008; Hafezalkotob et al., 2011; Xie et al., 2011; Whalley, 2011; Xiao et al., 2012; Xiao \& Xu, 2014; Shang \& Yang, 2015; Zhou et al., 2018; Yan et al., 2018). To the best of our knowledge, there is no research on CLSC management with risk-averse players' structure. So, the main contribution of this paper is the optimal decisions of the manufacturer, the retailer and the third party in a closed form under the risk-averse players' structure. Also, we design a contract to enhance the performance of decentralized CLSC to that of the centralized CLSC. Therefore, in this paper, by considering multi-level CLSC with one riskaverse manufacturer, one risk-averse retailer and one risk-averse third party, while the market demand function is uncertain and affected by the price and sales effort, four different modes of game theory models have been designed for decision-making. Channel power structure has an essential effect on the CLSC performance. Traditionally, manufacturers have enough power to be the channel leader and make decisions at first. However, in recent years, in some industries such as metal management and electronics, the collector acts as the channel leader (Choi et al., 2013). Thus, two decentralized structures including manufacturer-power and third party-power models and two cooperative models are established to investigate:

(i) The effect of various power structures on the optimum decisions and profits of the CLSC.

(ii) The impact of cooperative behaviors on the CLSC decision.

(iii) The optimal decision-making structures from the viewpoint of each member, the consumers and the whole chain.

(iv) The optimal values of wholesale price, retail price, sales effort and collecting rate under centralized and decentralized decision-making structures and different cooperative strategies.

(v) The coordination mechanism for the decentralized CLSC to have the same performance as the centralized chain.

Addressing the above significant open questions highlights the objectives and contributions of this research and this is believed to be the first paper which addresses the pricing, effort and collecting decisions in a three-level CLSC with the price and sales effort-dependent demand under various channel power structures and different cooperative behaviors while the members are risk-averse.

The rest of this paper is organized as follows. In Section 2, a literature review is provided. In Section 3 , price and sales effort sensitive uncertain market demand and CLSC members' random profit functions are formalized and related model assumptions are provided. In Section 4, different CLSC models are presented and the optimal solutions of the CLSC are calculated under different scenarios using game theory. Section 5 presents a contract to coordinate the decentralized CLSC. In Section 6, the analysis of the optimal results in various models and the efficiency of the designed coordination contract are proposed by numerical examples. Finally, we conclude the paper and outline the future research directions in Section 7. 


\section{Literature review}

A number of researchers have shown interest in the management of CLSC over the past decades. An extensive collection of literature on CLSCs can be found in articles by Govindan et al. (2013) and Govindan \& Soleimani (2017). Dhull \& Narwal (2016) proposed the literature on drivers and barriers of green supply chain management. Tang et al. (2010) considered a CLSC in which the retailers sell the same product on two markets. In this model, the sale price affects demand and the return rate of the used products. Cost-revenue sharing contract was designed for this problem. Chen et al. (2011) investigated the coordination of CLSC with multiple retailing markets with cost-revenue sharing contract. In this chain, sale price affects the demand and the recycling value is affected by the price of recycling and sales effort. Wei and Zhao (2013) considered the optimal pricing decision problem in a fuzzy CLSC with one manufacturer and two competitive retailers. In the study of Wu (2012), a manufacturer produces the new products and a remanufacturer recycles used products. The equilibrium of the remanufacturing efforts, price and service decisions have been obtained by game theory. Choi et al. (2013) studied the price decision in a CLSC including a manufacturer, a collector and a retailer. The performance of different structures has been analyzed under different leaderships. Guo \& Ma (2013) considered a two-level CLSC including a manufacturer and a retailer and they proposed a collecting price game model. Mahmoudzadeh et al. (2013) proposed a dynamic pricing problem in a CLSC involving a manufacturer and a retailer with uncertain demand and return. Wei et al. (2015) modeled a two-level CLSC with the symmetric and asymmetric information by using game theory. Optimal decisions about the wholesale price, the retail price and the collection rate have been obtained under four different game models. Huang et al. (2013) investigated optimal strategy in CLSC with two recycling channels where the retailer and third party collect the used product competitively. Chen et al. (2014) studied the coordination of a CLSC including two rival channels, a manufacturing chain and a remanufacturing chain, through wholesale price and revenue-sharing contracts. In the study of Ma \& Wang (2014), there was considered a CLSC including a manufacturer and a retailer where the demand is linear function of price. The problem has been solved using Stackelberg and Nash games. In a reverse supply chain where the customers return the used product as a function of discount offered by the retailer, Govindan and Popiuc (2014) studied the coordination of decentralized chain through revenuesharing contract.

De Giovanni (2014) studied a CLSC including a manufacturer and a retailer. Reverse revenue-sharing contract has been proposed for environmental cooperation and the advertisements have been shown to positively affect the return rates when the returns are numerous. Zu-Jun et al. (2016) considered a threelevel CLSC including a manufacturer, a retailer and two recyclers. Four different cooperative models have been solved and the results of these models have been compared. Huang et al. (2015) studied a CLSC with multi-dimensional return channels. In this CLSC, manufacturer, remanufacturer (retailer) or a third party collect the used products under pick-up and drop-off collection strategies. Optimum collection strategy has been obtained through Stackelberg game. Hong et al. (2015) investigated optimum decisions of pricing, collecting and local advertisement in a CLSC where the demand is affected by advertisement and retail price. A Stackelberg game has been modeled and a simple twopart tariff contract has been designed to coordinate the decentralized chain. In the study of De Giovanni et al. (2016), an optimum recycling program in a CLSC including a manufacturer and a retailer has been studied. The profit functions are affected by the return rate of used product through two methods, increasing in the sale of products and reducing in production cost. In the study of Gao et al. (2016), a CLSC consists of one manufacturer and one retailer has been considered to determine optimum decisions of price, sale efforts and collection activities. Three power structure models, including manufacturer Stackelberg, retailer Stackelberg and vertical Nash have been solved.

Aydin et al. (2016) investigated the coordination of a CLSC consists of a manufacturer, several retailers, and a remanufacturer for product line design using a game theoretical model. Ray and Mondal (2016) studied a two-period buyback pricing model which shows a competition between 
third party remanufacturer and original equipment manufacturer for market share in spare parts business. Chen et al. (2016) studied optimal replenishment quantity for new products and return rate of used products. Jawla \& Singh (2016) considered a reverse logistics inventory model for integrated production of new items and remanufacturing of returned items. Weraikat et al. (2016) studied the reverse chain of the pharmaceutical industry. They proposed a decentralized negotiation process to coordinate the reverse chain in collecting unused medicines from the customers. Zhang and Ren (2016) studied the coordination of a CLSC composed of a manufacturer, a remanufacturer, and a retailer. In this CLSC, the demand function is sensitive to price, and the new and remanufactured products are sold in the same market with different prices. Wang et al. (2017) proposed an information screening contract and a reward-penalty mechanism for a CLSC involving one manufacturer and one retailer under asymmetric information. Heydari et al. (2017) studied coordination of the two-echelon reverse supply chain with a manufacturer and a retailer with increasing fee and quantity discounts contracts. Masoudipour et al. (2017) considered a CLSC based on quality of returned products to determine whether a return should be recycled, repaired or remanufactured. Modak et al. (2018) considered a two- echelon CLSC where demand is sensitive with price and quality level of the product to investigate the effects of recycling and product quality level on pricing decision.

All of the above papers assume that the CLSC members are risk-neutral. However, in many cases, the supply chain members, in addition to increasing their profits, seek to reduce their risk. Also, most papers consider CLSC with two parties and demand function is only sensitive to price. So, we investigate the pricing, effort and collect decisions in a three-level CLSC with the price and sales effort dependent-demand while the members are risk-averse. To the best of our knowledge, there are found very few paper results on price and effort decisions in a three-level CLSC under various channel power and different cooperative structures. Also, there is no research result on CLSC management with riskaverse players' structure. The inclusion of the risk aversion of the parties is considered which highlighting the objectives and contributions of this paper.

\section{Problem description}

This paper considers a CLSC consisting of one risk-averse manufacturer, one risk-averse retailer and one risk-averse third party. In the forward channel, the manufacturer gives the products with unit wholesale price $w$ to the retailer and the products will be sold to the customers with unit retail price $p$ by the retailer. Sales effort $e$ made by the retailer can positively impact the market demand. The cost of sales effort is considered as an increasing convex function of $e$, which is defined as $\eta e^{2} / 2$. Similar quadratic cost function has been used in the previous literature (Wu, 2012; Wei et al., 2015; Gao et al., 2016). In the reverse channel, the third party collects the used products with return rate $\tau$ and gives them to the manufacturer with the unit transfer cost $f$ which is an exogenous variable. Similar to Savaskan et al. (2006), Wu (2012) and Wei et al. (2015), the third party's investment in collection activities is defined as $C_{T}(\tau)=\lambda \tau^{2}$, where $\lambda$ is a scaling parameter. It is assumed that the parameter $\lambda$

is large enough, $\lambda>\max \left\{\left(c_{m}-c_{r}\right) b f / 4,\left(c_{m}-c_{r}\right)^{2} b / 8\right\}$, to ensure that the different profit functions behave well and possess a unique optimum (Savaskan et al., 2006). Average manufacturing cost of each unit is $c_{m}(1-\tau)+c_{r} \tau$ in which $c_{m}$ is the unit-manufacturing cost of new products and $c_{r}$ is the unit-remanufacturing cost of used products $\left(c_{m}>c_{r}\right)$; so, the cost-saving of remanufacturing will be as $\Delta=c_{m}-c_{r}$. Since the market environment is often uncertain, the market demand function is assumed to be uncertain and linear, which is defined as $\tilde{D}=D+\varepsilon$ where $D=a-b p+L e(a, b, \mathrm{~L}>0, a>b p)$ is the expected demand as a function of the retail price and the sales-effort where $a$ represents the initial potential of the market when the price is zero without any effect from sales effort on demand; coefficients $b$ and $L$ are the sensitivity of demand to price and sales effort, respectively, and $\varepsilon$ is a nonnegative random variable, referred to as demand uncertainty, which is independent of $p$ and $e$. Without 
loss of generality, we assume $\varepsilon \approx N\left(0, \sigma^{2}\right)$, where the mean of $\varepsilon$ is zero and $\sigma^{2}$ is the variance of $\varepsilon$. Such a linear demand function is widely used in CLSC models (Savaskan et al., 2006; Zu-Jun et al., 2016; Choi et al., 2013; Wei et al., 2015; Gao et al., 2016). The third party is assumed to positively impact the returns by investing in green programs, such as promoting recycling policies, logistics services, symbolic and monetary incentives. The main product and the remanufactured product have the same quality and they have similar price in the market (Savaskan \& Van Wassenhove, 2006).

All products which are collected from the customers can be remanufactured successfully (c.f., Gao et al., 2016). The manufacturer initially remanufactures the collected products to benefit from cost-saving. Usually, the used products are not enough to meet the demand and the manufacturer produces new products from row materials (c.f., Gao et al., 2016). The unit-collecting cost, the total variable costs of each unit that is required to be delivered to the manufacturer's factory, is not more than the cost-saving of remanufacturing; so, the remanufacturing will be economic (c.f., Zu-Jun et al., 2016). Since the demand is random, the profit of the members is also random. Similar to Xiao and Yang (2008), and Hafezalkotob et al. (2011), it is assumed that the random profit is evaluated based on the MeanVariance function. So, the manufacturer's random profit is $\tilde{\pi}_{M}=\left(w-c_{m}+\Delta \tau-f \tau\right) \tilde{D}$.

Consequently, the manufacturer's utility is:

$$
u_{M}=E\left(\tilde{\pi}_{M}\right)-\lambda_{m} \operatorname{Var}\left(\tilde{\pi}_{M}\right) / 2=\left(w-c_{m}+(\Delta-f) \tau\right)(a-b p+L e)-\lambda_{m}\left(w-c_{m}+(\Delta-f) \tau\right)^{2} \frac{\sigma^{2}}{2},
$$

where $\lambda_{m} \geq 0$ is the degree of risk aversion for the manufacturer. The last term in Eq. (1) is the manufacturer's risk cost incurred by the random profit. Similar to Eq. (1), the retailer's utility is

$$
u_{R}=(p-w)(a-b p+L e)-\frac{\eta e^{2}}{2}-\lambda_{R}(p-w)^{2} \frac{\sigma^{2}}{2},
$$

where $\lambda_{R} \geq 0$ is the degree of risk aversion for the retailer. Similarly, the third party's utility is

$$
u_{T}=f \tau(a-b p+L e)-\lambda \tau^{2}-\lambda_{T}(f \tau)^{2} \frac{\sigma^{2}}{2},
$$

where $\lambda_{T} \geq 0$ is the degree of risk aversion for the third party.

\section{Different decision-making models of CLSC}

In this section, four game models are established to investigate the impact of various channel power and cooperative structures on the optimal decisions and profits of CLSC.

\subsection{Centralized model (Model C)}

In order to provide a benchmark scenario, we consider the centralized model to compare the profit and the performance of the other decentralized and cooperative models with it. In centralized model, there is a single decision maker that aims to maximize the performance of whole system. Since there is only one entity, the transfer prices between the manufacturer and the third party and also between the manufacturer and the retailer are insignificant. So, only the optimal retail price, sales effort, and return rate should be calculated. In this model, the total utility function is as follows,

$$
\max _{p, e, \tau} u_{C}=\left(p-c_{m}+\Delta \tau\right)(a-b p+L e)-\lambda \tau^{2}-\frac{\eta e^{2}}{2}-\lambda_{m}\left(p-c_{m}+\Delta \tau\right)^{2} \frac{\sigma^{2}}{2}
$$

Proposition 1: The total utility function of chain, $u_{C}$, is concave in $p, e$ and $\tau$ if $\eta\left(2 b+\lambda_{m} \sigma^{2}\right)-\mathrm{L}^{2}>0$ and $4 b \eta \lambda+2 L^{2} \Delta^{2} \lambda_{m} \sigma^{2}>2 \eta \lambda_{m} \sigma^{2}\left(\lambda+\Delta^{2} \lambda_{m} \sigma^{2}\right)+2 L^{2} \lambda+b^{2} \Delta^{2} \eta$.

All proofs are proposed in appendix A. 
Thus, from the first order derivative, equilibrium for retail price, sales effort and return rate are

$$
\begin{aligned}
p_{C}^{*} & =\frac{a \eta\left(2 \lambda-b \Delta^{2}\right)+2 \lambda c_{m}\left(b \eta+\eta \lambda_{m} \sigma^{2}-L^{2}\right)}{A}, \\
e_{C}^{*} & =\frac{2 L \lambda\left(a-b c_{m}\right)}{A}, \\
\tau_{C}^{*} & =\frac{b \eta \Delta\left(a-b c_{m}\right)}{A},
\end{aligned}
$$

where $A=2 \eta \lambda\left(2 b+\lambda_{m} \sigma^{2}\right)-2 L^{2} \lambda-b^{2} \Delta^{2} \eta$.

By substituting the above optimal variables in utility function given in Eq. (4), we can derive the total utility of the chain as follows,

$$
u_{C}^{*}=\frac{\eta \lambda\left(a-b c_{m}\right)^{2}}{A} \text {. }
$$

\subsection{Models of CLSC under various channel power and cooperative structures}

In many real life cases, each participant of CLSC tries to raise his/her benefit function. Channel power structure has an essential effect on CLSC performance. Traditionally, manufacturers have enough power to be the channel leader and make decisions at first. However, in recent years, giant collectors such as SIMS Metal Management, AER Worldwide and IBM's Global Asset Recovery Services take the market power and act as the channel leader in the CLSC. So, two channel power structures including manufacturer Stackelberg and third party Stackelberg models are considered. Also, there are different coalition structures in CLSCs in real life. For example, the "big three" auto manufacturers in the United States (i.e., GM, Chrysler, Ford) have established a long-term cooperative partnership with recyclers. In some companies, such as Dell and IBM, a coalition includes a manufacturer and a recycler has been formed to make products and recycle used products. Moreover, in some situations, the manufacturer and the retailer such as $\mathrm{P} \& \mathrm{G}$ and Wal-Mart can establish a good cooperative relationship. Other examples for such cooperation are Xerox and Eastman Kodak Company which established good cooperative relationships with retailers. So, two cooperative models involving model MT (the collaboration mode of the manufacturer and the third party) and model MR (the collaboration mode of the manufacturer and the retailer) are established in this section.

\subsubsection{Manufacturer - power model (Model D)}

In this model, each participant seeks to maximize his utility function. The decision sequence is as follows: firstly, the manufacturer determines his wholesale price. Then, the third party determines his return rate. After that, the retailer determines his retail price and sales effort.

Proposition 2: The retailer's utility function is concave in $p$ and $e$ if $\eta\left(2 b+\lambda_{R} \sigma^{2}\right)-L^{2}>0$.

Then, from the first order derivative, the optimal retail price and sales effort are obtained as

$$
\begin{aligned}
& p^{*}=\frac{-\eta(w b+a)+w\left(L^{2}-\eta \lambda_{R} \sigma^{2}\right)}{A_{1}}, \\
& e^{*}=\frac{L(w b-a)}{A_{1}},
\end{aligned}
$$

with $A_{1}=L^{2}-\eta\left(2 b+\lambda_{R} \sigma^{2}\right)$. 
Since the third party knows the retailer's reaction functions given by (9) and (10) for any $p$ and $e$ values he/she sets, his/her utility will be obtained by placing the above optimal variables in third party's utility function, $u_{T}$.

Proposition 3: the third party's utility is concave in $\tau$. Thus, from the first order derivative we have

$$
\tau^{*}=\frac{f \eta(w b-a)\left(b+\lambda_{R} \sigma^{2}\right)}{A_{1} B},
$$

where $B=2 \lambda+\lambda_{T} \sigma^{2} f^{2}$. Since the manufacturer knows the followers' reaction functions given by (9)(11), his utility will be obtained by placing them in manufacturer's utility function.

Proposition 4: The manufacturer's utility function $u_{M}$, is concave in $w$ if

$$
b\left(A_{1} B+E\right)\left(2 k B-\lambda_{m} \sigma^{2}\left(A_{1} B+E\right)\right)>0 .
$$

So, from the first order derivative, equilibrium for wholesale price is as follows.

$$
w_{D}^{*}=\frac{A_{1} B^{2} k\left(a+b c_{m}\right)+2 a B E k-\lambda_{m} \sigma^{2}\left(A_{1} B+E\right)\left(A_{1} B b c_{m}+a E\right)}{b\left(A_{1} B+E\right)\left(2 k B-\lambda_{m} \sigma^{2}\left(A_{1} B+E\right)\right)}
$$

with $k=b \eta\left(b+\lambda_{R} \sigma^{2}\right), E=f(\Delta-f) k$. By substituting Eq. (12) into Eqs. (9-11), we can derive equilibrium for retail price, sales effort and return rate. Then, by placing optimal variables in objective functions (1)-(3), we can obtain maximal utility of members under decentralized model D as follows.

$$
\begin{aligned}
& u_{M}^{D^{*}}=\frac{-k^{2} B^{2}\left(a-b c_{m}\right)^{2}}{2 b^{2}\left(A_{1} B+E\right)\left(2 k B-\lambda_{m} \sigma^{2}\left(A_{1} B+E\right)\right)} \\
& u_{R}^{D^{*}}=\frac{B^{2}\left(a-b c_{m}\right)^{2}\left[\lambda_{m} \sigma^{2}\left(A_{1} B+E\right)-k B\right]^{2}\left[\eta k+b \eta\left(b \eta-L^{2}\right)\right]}{2 b\left(A_{1} B+E\right)^{2}\left[2 k B-\lambda_{m} \sigma^{2}\left(A_{1} B+E\right)\right]^{2}} \\
& u_{T}^{D^{*}}=\frac{f^{2} k^{2} B\left(a-b c_{m}\right)^{2}\left[\lambda_{m} \sigma^{2}\left(A_{1} B+E\right)-k B\right]^{2}}{2 b^{2}\left(A_{1} B+E\right)^{2}\left[2 k B-\lambda_{m} \sigma^{2}\left(A_{1} B+E\right)\right]^{2}}
\end{aligned}
$$

\subsubsection{The co-manufacturer and third party model (Model MT)}

In this model, the manufacturer and the third party cooperate with each other. So, they will be considered as a decision-maker and there is no transfer price between them. They decide about the wholesale price and the return rate as the leader of Stackelberg. Then, the retailer determines sales effort and retail price as the follower of Stackelberg.

From Proposition 2, the retailer's utility function, $u_{R}$, is concave in $p$ and $e$ if $\eta\left(2 b+\lambda_{R} \sigma^{2}\right)-L^{2}>0$. So, from the first order derivative we have

$$
\begin{aligned}
p^{*} & =\frac{-\eta(w b+a)+w\left(L^{2}-\eta \lambda_{R} \sigma^{2}\right)}{A_{1}} \\
e^{*} & =\frac{L(w b-a)}{A_{1}}
\end{aligned}
$$

Since the manufacturer and third party as the leader know the follower's reaction functions given by Eqs. (16-17), their utility will be obtained by placing (16)-(17) in total utility function of the manufacturer and third party, $u_{M T}$. 
Proposition 5: The total utility function of manufacturer and third party, $u_{M T}$, is concave in $w$ and $\tau$ if $A_{1} \lambda_{m} \sigma^{2}>2 k$ and $2 b^{2} A_{1} \lambda\left(A_{1} \lambda_{m} \sigma^{2}-2 k\right)-b^{2} k^{2} \Delta^{2}>0$. Thus, from the first order derivative, equilibrium for wholesale price and return rate are obtained as follows.

$$
\begin{aligned}
& w_{M T}^{*}=\frac{2 b^{2} A_{1} \lambda c_{m}\left(A_{1} \lambda_{m} \sigma^{2}-k\right)-a b k\left(2 \lambda A_{1}+k \Delta^{2}\right)}{A_{3}}, \\
& \tau_{M T}^{*}=\frac{b \Delta k^{2}\left(a-b c_{m}\right)}{A_{3}},
\end{aligned}
$$

where $A_{3}=2 b^{2} A_{1} \lambda\left(A_{1} \lambda_{m} \sigma^{2}-2 k\right)-b^{2} \Delta^{2} k^{2}$. By combining Eq. (18) and Eq. (19) with Eqs. (16-17) and members' utility functions, we can derive equilibrium for retail price, sales effort and the maximum utility of the members.

\subsubsection{Third party- power model (Model T)}

In this model, the third party has the power and takes the channel leadership position. This happens when there is a big and powerful third party such as SIMS Metal Management and AER Worldwide in the market. Firstly, the third party decides about his return rate as the leader. Then, the manufacturer decides about the wholesale price. Afterwards, the retailer determines the retail price and sales effort. From Proposition 2, the retailer's utility function, $u_{R}$, is concave in $p$ and $e$ if $\eta\left(2 b+\lambda_{R} \sigma^{2}\right)-L^{2}>0$. So, from the first order derivative, the optimal retail price and sales effort of the retailer are given as

$$
\begin{aligned}
& p^{*}=\frac{-\eta(w b+a)+w\left(L^{2}-\eta \lambda_{R} \sigma^{2}\right)}{A_{1}}, \\
& e^{*}=\frac{L(w b-a)}{A_{1}} .
\end{aligned}
$$

Since the manufacturer knows the retailer's reaction functions given by Eqs. (20-21), his utility will be obtained by placing the above optimal variables in manufacturer's utility function.

Proposition 6: the manufacturer's utility, $u_{M}$, is concave in $w$ if $b\left(A_{1} \lambda_{m} \sigma^{2}-2 k\right)>0$. Then, from the first order derivative we have

$$
w^{*}=\frac{b\left(\tau(\Delta-f)-c_{m}\right)\left(k-A_{1} \lambda_{m} \sigma^{2}\right)-a k}{b\left(A_{1} \lambda_{m} \sigma^{2}-2 k\right)} .
$$

Since the third party knows the followers' reaction functions given by (20)-(22), his utility will be obtained by placing them in third party's utility function.

Proposition 7: The third party's utility function, $u_{T}$, is concave in $\tau$ if $2 b E\left(k-A_{1} \lambda_{m} \sigma^{2}\right)+b A_{1} \mathrm{~B}\left(A_{1} \lambda_{m} \sigma^{2}-2 k\right)>0$. So, from the first order derivative, equilibrium for return rate is obtained as follows.

$$
\tau_{T}^{*}=\frac{f k\left(k-A_{1} \lambda_{m} \sigma^{2}\right)\left(a-b c_{m}\right)}{2 b E\left(k-A_{1} \lambda_{m} \sigma^{2}\right)+b A_{1} \mathrm{~B}\left(A_{1} \lambda_{m} \sigma^{2}-2 k\right)} .
$$

By combining Eq. (23) with Eqs. (20-22) and members' utility functions, we can derive equilibrium for wholesale price, retail price, sales effort and the maximum profits of the members.

\subsubsection{The co-manufacturer and retailer model (Model MR)}

In this model, firstly, the third party decides about his return rate as the leader of Stackelberg. Then, manufacturer and retailer form a coalition and cooperate with each other. So, they will be considered 
as a decision-maker and the wholesale price is meaningless; they determine the retail price and sales effort as the follower of Stackelberg.

Proposition 8: The total utility function of manufacturer and retailer, $u_{M R}$, is concave in $p$ and $e$ with $\eta\left(2 b+\lambda_{m} \sigma^{2}\right)-L^{2}>0$. Then, from the first order derivative, we have,

$$
\begin{aligned}
& p^{*}=\frac{\eta\left(a+b c_{m}\right)-\eta b \tau(\Delta-f)+\left(\tau(\Delta-f)-c_{m}\right)\left(L^{2}-\eta \lambda_{m} \sigma^{2}\right)}{A_{4}}, \\
& e^{*}=\frac{L b \tau(\Delta-f)+L\left(a-b c_{m}\right)}{A_{4}}
\end{aligned}
$$

with $A_{4}=\eta\left(2 b+\lambda_{m} \sigma^{2}\right)-L^{2}$. Since, the leader (third party) knows the follower's reaction functions given by (24)-(25), his utility will be obtained by placing Eqs. (24-25) in utility function of third party.

Proposition 9: The utility function of third party, $u_{T}$, is concave in $\tau$ if $A_{4} B-2 f(\Delta-f) \eta b\left(b+\lambda_{m} \sigma^{2}\right)>0$. So, from the first order derivative, equilibrium for third party's return rate is given as

$$
\tau_{M R}^{*}=\frac{f \eta\left[b\left(a-b c_{m}\right)-\lambda_{m} \sigma^{2}\left(a+b c_{m}\right)\right]}{A_{4} B-2 f(\Delta-f) \eta b\left(b+\lambda_{m} \sigma^{2}\right)} .
$$

By combining Eq. (26) with Eqs. (24-25) and members' utility functions, we can derive equilibrium for retail price, sales effort and the corresponding maximum utility of the member.

\section{Coordination mechanism}

In this section, based on the low price promotion strategy, a contract is proposed to improve the performance of decentralized CLSC to that of the centralized CLSC. Since, based on the result presented in Section 6, the lowest performance of chain is related to Model D, we present the coordination contract for model D because the significance of coordination is biggest in this model. Unlike the two-part tariff contract in which the manufacturer offers the retailer a low wholesale price and charges a fixed franchise fee (Govindan et al., 2013), in this contract, the manufacturer gives the products with unit wholesale price $w$ to the retailer which is equal to the wholesale price of decentralized model D and fixed fees are charged by the downstream members (retailer and third party). The retailer sells products with the price equal to the retail price of centralized model and provides great sales effort the same as that in the centralized model. The third party exerts great collection effort as much as that in centralized CLSC. The low price and more effort which provided by the retailer and more rate of return that provided by the third party will increase the demand and thus the profit of manufacturer. But the retailer and third party's profit will decrease. Therefore, if the manufacturer wants to encourage retailer and third party to make decisions similar to the centralized mode, he must share this additional revenue with them. So, the manufacturer, as the Stackelberg leader, to enforce the contract, allocates a fixed amount $F_{1}$ to the third party in the reverse channel and a fixed amount $F_{2}$ to the retailer in the forward channel. Theses fixed amount are the negotiated value and influenced by the bargaining power that each member carries. The manufacturer and the third party agree on $F_{1}$ and the manufacturer and the retailer agree on $F_{2}$, which ensures that their profits will not be lower than those derived in decentralized CLSC. Thus, utility functions which are designed according to the contract will be as follows,

$$
\begin{aligned}
& u_{M}^{r F}=\left(w-c_{m}+\Delta \tau\right)(a-b p+L e)-\lambda_{m}\left(w-c_{m}+\Delta \tau\right)^{2} \frac{\sigma^{2}}{2}-F_{1}-F_{2}, \\
& u_{T}^{r F}=F_{1}-\lambda \tau^{2},
\end{aligned}
$$


$u_{R}^{r F}=F_{2}-\frac{\eta e^{2}}{2}$.

By substituting the optimal values of the variables in the above utility functions and establishing terms of win-win which means $u_{T}^{r F^{*}}>u_{T}^{\mathrm{D}^{*}}, u_{R}^{r F^{*}}>u_{R}^{\mathrm{D}^{*}}, u_{M}^{r F^{*}}>u_{M}^{\mathrm{D}^{*}}$, we can derive the optimal fixed amount $F_{1}$ and $F_{2}$ as follows.

$$
\begin{aligned}
& F_{1}^{*}>\frac{f^{2} k^{2} B\left(a-b c_{m}\right)^{2}\left[\lambda_{m} \sigma^{2}\left(A_{1} B+E\right)-k B\right]^{2}}{2 b^{2}\left(A_{1} B+E\right)^{2}\left[2 k B-\lambda_{m} \sigma^{2}\left(A_{1} B+E\right)\right]^{2}}+\frac{\lambda b^{2} \eta^{2} \Delta^{2}\left(a-b c_{m}\right)^{2}}{A^{2}}, \\
& F_{2}^{*}>\frac{B^{2}\left(a-b c_{m}\right)^{2}\left[\lambda_{m} \sigma^{2}\left(A_{1} B+E\right)-k B\right]^{2}\left[\eta k+b \eta\left(b \eta-L^{2}\right)\right]}{2 b\left(A_{1} B+E\right)^{2}\left[2 k B-\lambda_{m} \sigma^{2}\left(A_{1} B+E\right)\right]^{2}}+\frac{2 L^{2} \lambda^{2}\left(a-b c_{m}\right)^{2} \eta}{A^{2}}, \\
& F_{1}^{*}+F_{2}^{*}<\frac{k^{2} B^{2}\left(a-b c_{m}\right)^{2}}{2 b^{2}\left(A_{1} B+E\right)\left(2 k B-\lambda_{m} \sigma^{2}\left(A_{1} B+E\right)\right)}+\frac{2 \eta^{2} \lambda^{2}\left(a-b c_{m}\right)^{2}\left(2 b+\lambda_{m} \sigma^{2}\right)}{A^{2}} .
\end{aligned}
$$

Thus, if the manufacturer pays a fixed amount $F_{1}$ to the third party and a fixed amount $F_{2}$ to the retailer satisfying the range given in inequality (30)-(32), the retailer, the third party and the manufacturer have opportunity to gain extra profit compared to the decentralized scenario D. However, the relative bargaining powers of the chain's partners will determine acceptable values of $F_{1}$ and $F_{2}$ to the members of the CLSC.

Observation 1. The performance of CLSC under decentralized model D can be improved by the designed contract to the level of centralized CLSC. The manufacturer and the third party agree on $F_{1}$ and the manufacturer and the retailer agree on $F_{2}$, which guarantees that their profits will be higher than those of decentralized scenario D. In this contract, the customers buy the product with a lower price and more used products will be collected. So, this contract is advantageous for the members of CLSC, the customers, and the environmental issues. This implicates that sustainable operation of the CLSC can be facilitated through coordination of chain participants.
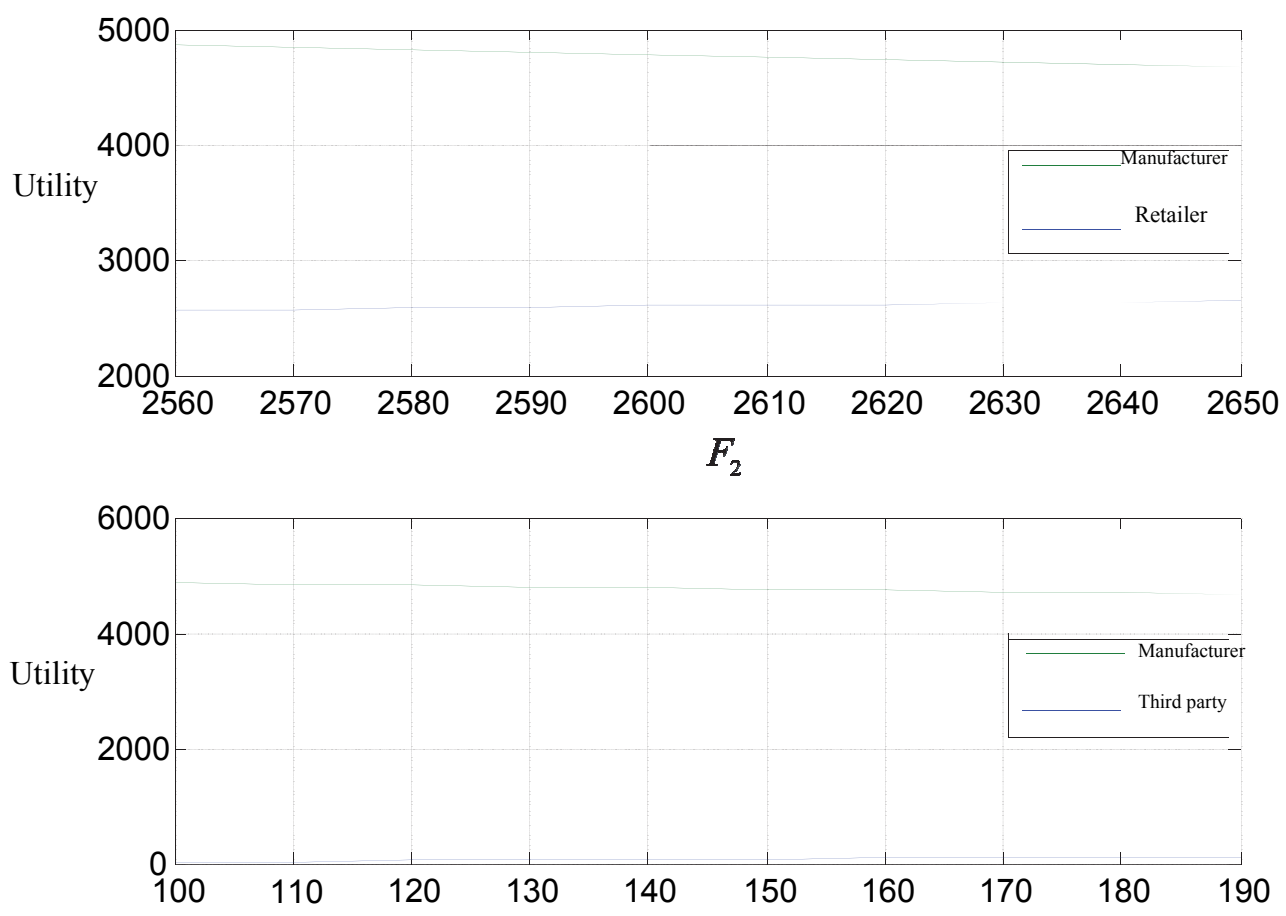

Fig. 1. Members' utility urlder coordination contract 
The structure of member's utility functions under coordination contract shows that as $F_{1}$ increases, the manufacturer's profit decreases and the third party's profit increases. Also, as $F_{2}$ increases the manufacturer's profit decreases and the retailer's profit increases. Graphical representations of members' utility functions for the above ranges are given in Fig. 1. Also, the graphical representations of the manufacturer and the retailer's profit ratio under coordination mechanism and the manufacturer and the third party's profit ratio under coordination contract are shown in Fig. 2.
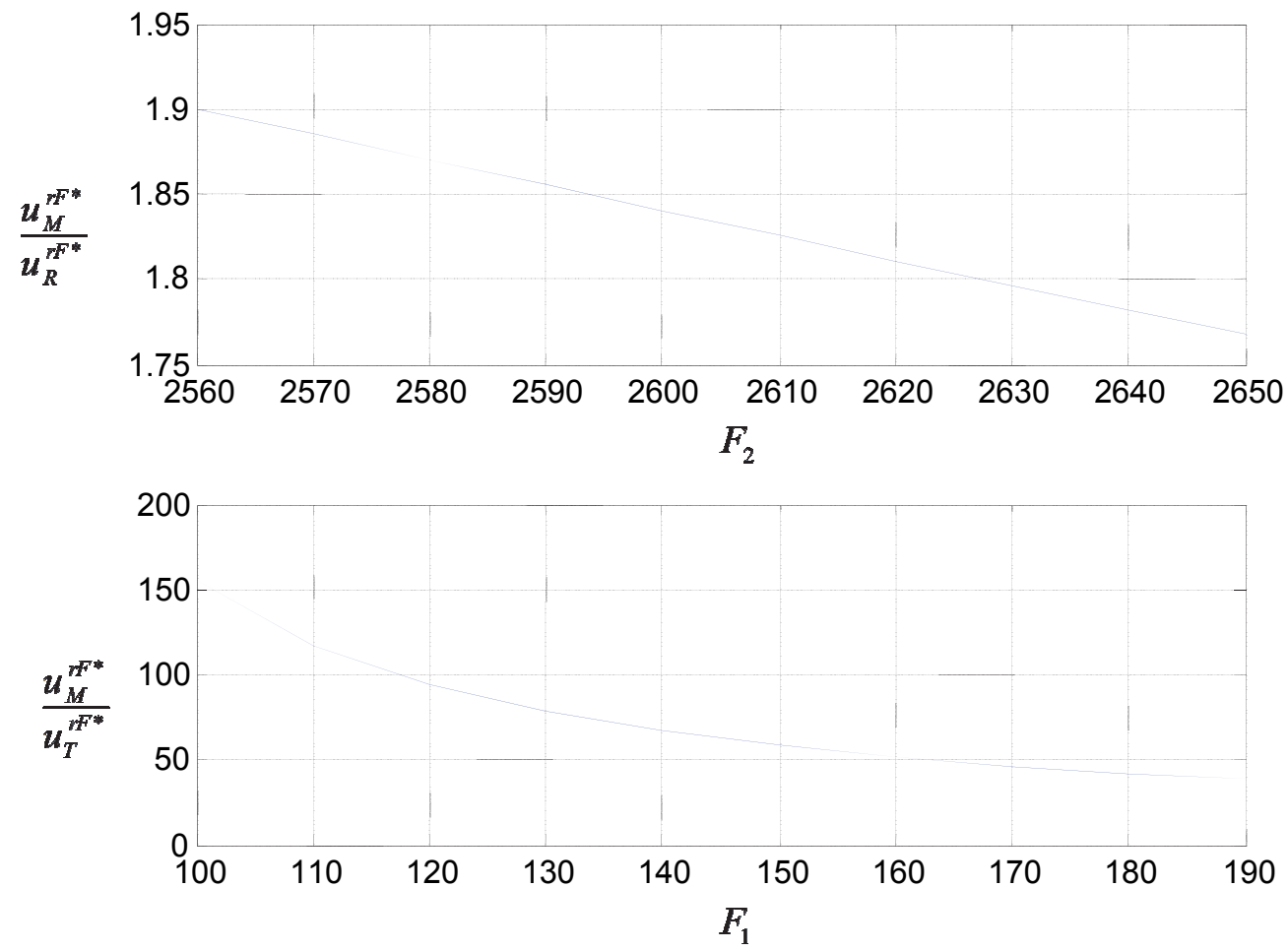

Fig. 2. a. Ratio of the manufacturer's and the retailer's utility under coordination contract

b. Ratio of the manufacturer's and the third party's utility under coordination contract

\section{Numerical analysis}

Due to the results proposed in Section 4 that are in a very sophisticated form, it is complicated to compute the profits and to compare the results analytically. So, in this section, the numerical examples are provided to analyze the optimal results of various models and the efficiency of the designed contract. Also, the best decision-making structure from the viewpoint of each member, customers and the whole chain is investigated. Accordingly, six numerical examples are considered where the parameter values of these illustrations are shown in Table 1 and the other parameters are $a=200, c_{m}$ $=30.0, c_{r}=27.0, f=1.5$ and $b=0.8$.

Table 1

Values of parameters for numerical examples

\begin{tabular}{ccccccc}
\hline case & $L$ & $\eta$ & $\lambda$ & $\lambda_{m}$ & $\lambda_{R}$ & $\lambda_{T}$ \\
\hline 1 & 0.3 & 100 & 150 & 0.5 & 1 & 0.5 \\
2 & 0.3 & 200 & 150 & 0.5 & 1 & 0.5 \\
3 & 0.3 & 100 & 300 & 0.5 & 1 & 0.5 \\
4 & 0.7 & 100 & 150 & 0.5 & 1 & 0.5 \\
5 & 0.3 & 100 & 150 & 0.5 & 1 & 1 \\
6 & 0.3 & 100 & 150 & 0.5 & 0.5 & 0.5 \\
\hline
\end{tabular}


For example, in case 1 , the market based $a$ is medium, price elasticity $b$ is sensitive, sales effort elasticity $L$ is low sensitive, the effort cost coefficients $\eta$ is Low, the collection efficiency $\lambda$ is medium, the risk aversion of manufacturer $\lambda_{m}$ is medium, the risk aversion of retailer $\lambda_{R}$ is high and the risk aversion of third party $\lambda_{T}$ is medium.

\subsection{Analysis of equilibrium results and insights}

The optimal values of the CLSC under different scenarios for each numerical example are calculated. The corresponding equilibrium results of various models are presented in Table 2. Our results can be summarized as following.

1. The optimal total utility of chain is ordered as $u_{C}{ }_{C}>u^{*}{ }_{M R}>u_{T}^{*}>u^{*}{ }_{M T}>u_{D}^{*}$.

As it can be seen, among the cooperative models, Model MR is better than model MT; and both of them have more profit than that in decentralized model D. In decentralized model T, where the third party is the leader, the total utility of chain is more than that in cooperative model MT.

2. With regard to the centralized model, we have the followings:

- In model MR, cooperation mode of manufacturer and retailer, total utility of chain is more than that in other models. Total utility of chain decreases in models MR, T, MT, and D.

- The retail price increases in models MR, MT, T, and D respectively. So, the decision-making model MR is the best model from the viewpoint of price-sensitive customers.

- The sales effort of the retailer decreases in models MR, MT, T and D, respectively.

- The return rate of third party decreases in models MT, D, T and MR, respectively. This result reveals that when the manufacturer cooperates with the third party, more used products are collected from the market. Therefore, the government should persuade the manufacturer and collector to take part in collecting used products.

- The market demand will decrease in models MR, MT, T and D, respectively. This result reveals that when the retailer cooperates with the manufacturer, the retail price is decreased and more products will be sold in the market.

- The retailer's utility will decrease in models MT, T and D, respectively. This result reveals that the partnership between the manufacturer and collector can improve profit of the retailer.

- The manufacturer's utility decrease in models $\mathrm{T}$ and $\mathrm{D}$, respectively.

- The third party's utility will decrease in models T, D and MR respectively.

3. In model MR, the performance of chain, the chain's utility and the optimal values of decision variables, is very close to the performance of centralized model; except the return rate and third party's profit which are the least in model MR.

4. From the viewpoint of manufacturer and retailer, model MR where they cooperate as the follower of Stackelberg is better than other models; because the total utility of manufacturer and retailer has increased and this cooperation is advantageous for them.

5. In model $\mathrm{T}$, where the third party has the power and takes the channel leadership position, manufacturer's profit is increased and is more than that in decentralized model D where the manufacturer is leader; i.e. the leadership power of third party has increased the profit of manufacturer and it is beneficial for the manufacturer. So, it is not the best scenario for the manufacturer to act as the channel leader. Instead, having the third party as the supply chain leader can lead to the better result. 
6. Third party's utility in decentralized model $\mathrm{T}$ is greater than that in other models, i.e. the leadership power of third party has increased his profit. While, in model MR, the third party has the power but the cooperation between manufacturer and retailer has decreased the profit of third party so that his utility is the least in model MR.

7. According to the above observations, one can get that cooperation between manufacturer and retailer, model MR, is advantageous for these two members and the whole chain. Also, the cooperation between the retailer and the manufacturer could reduce retail prices. So, from the viewpoint of customer, decision-making model MR is the best model because it has the lowest retail price. Supply chain efficiency can be improved by cooperation strategy.

Table 2. The equilibrium results of different models in six cases

\begin{tabular}{|c|c|c|c|c|c|c|c|c|c|c|}
\hline & Model & $w^{*}$ & $p^{*}$ & $e^{*}$ & $\tau^{*}$ & $D^{*}$ & $U_{M}^{*}$ & $U_{R}{ }^{*}$ & $U_{T}^{*}$ & $U_{C}^{*}$ \\
\hline \multirow{5}{*}{ Case 1} & $\mathbf{C}$ & N/A & 112.588 & 0.2538 & 0.6769 & 110.005 & N/A & N/A & N/A & 7446.5 \\
\hline & D & 106.011 & 150.33 & 0.1329 & 0.3974 & 79.775 & 4644.2 & 2552.60 & 23.776 & 7220.57 \\
\hline & $\mathbf{T}$ & 105.4085 & 149.913 & 0.1335 & 0.3958 & 80.109 & 4644.39 & 2574.02 & 23.974 & 7242.39 \\
\hline & MT & 104.967 & 149.608 & 0.1339 & 0.4223 & 80.353 & N/A & 2589.76 & N/A & 7235.79 \\
\hline & MR & N/A & 113.781 & 0.2516 & 0.0689 & 109.05 & N/A & N/A & 10.549 & 7395.87 \\
\hline \multirow{5}{*}{ Case2 } & $\mathrm{C}$ & N/A & 112.570 & 0.1269 & 0.6768 & 109.981 & N/A & N/A & N/A & 7444.9 \\
\hline & D & 106.007 & 150.32 & 0.0664 & 0.3973 & 79.763 & 4643.14 & 2552.30 & 23.769 & 7219.22 \\
\hline & $\mathbf{T}$ & 105.4044 & 149.903 & 0.0667 & 0.3957 & 80.097 & 4643.33 & 2573.72 & 23.967 & 7241.02 \\
\hline & MT & 104.963 & 149.597 & 0.0669 & 0.4222 & 80.341 & N/A & 2589.45 & N/A & 7234.42 \\
\hline & MR & N/A & 113.763 & 0.1258 & 0.0688 & 109.026 & N/A & N/A & 10.544 & 7394.29 \\
\hline \multirow{5}{*}{ Case 3} & $\mathbf{C}$ & N/A & 113.219 & 0.2526 & 0.3369 & 109.5 & N/A & N/A & N/A & 7412.3 \\
\hline & D & 105.904 & 150.26 & 0.1330 & 0.1992 & 79.834 & 4631.91 & 2556.38 & 11.927 & 7200.22 \\
\hline & $\mathbf{T}$ & 105.6022 & 150.047 & 0.1333 & 0.1988 & 80.001 & 4631.95 & 2567.13 & 11.977 & 7211.06 \\
\hline & MT & 105.383 & 149.896 & 0.1335 & 0.2105 & 80.123 & N/A & 2574.91 & N/A & 7207.6 \\
\hline & MR & N/A & 113.813 & 0.2515 & 0.0343 & 109.024 & N/A & N/A & 5.264 & 7387.12 \\
\hline \multirow{5}{*}{ Case 4} & $\mathbf{C}$ & N/A & 112.747 & 0.5934 & 0.6782 & 110.217 & N/A & $\mathrm{N} / \mathrm{A}$ & $\mathrm{N} / \mathrm{A}$ & 7460.9 \\
\hline & D & 106.048 & 150.42 & 0.3106 & 0.3979 & 79.877 & 4653.61 & 2555.22 & 23.837 & 5226.12 \\
\hline & $\mathbf{T}$ & 105.444 & 150.007 & 0.3119 & 0.3963 & 80.212 & 4653.81 & 2576.71 & 24.036 & 7254.55 \\
\hline & MT & 105.001 & 149.700 & 0.3128 & 0.4232 & 80.458 & N/A & 2592.51 & N/A & 7247.98 \\
\hline & MR & N/A & 113.941 & 0.5883 & 0.0689 & 109.258 & N/A & N/A & 10.589 & 7410.03 \\
\hline \multirow{5}{*}{ Case 5} & $\mathrm{C}$ & N/A & 112.588 & 0.2538 & 0.6769 & 110.005 & N/A & N/A & N/A & 7446.5 \\
\hline & D & 106.01 & 150.33 & 0.1329 & 0.3959 & 79.775 & 4644.11 & 2552.63 & 23.687 & 7220.42 \\
\hline & $\mathbf{T}$ & 105.909 & 149.914 & 0.1335 & 0.3943 & 80.108 & 4644.29 & 2573.97 & 23.884 & 7242.15 \\
\hline & MT & 104.967 & 149.608 & 0.1339 & 0.4223 & 80.353 & N/A & 2589.76 & N/A & 7235.79 \\
\hline & MR & N/A & 113.781 & 0.2516 & 0.0685 & 109.05 & N/A & N/A & 10.509 & 7395.81 \\
\hline \multirow{5}{*}{ Case6 } & $\mathbf{C}$ & N/A & 112.588 & 0.2538 & 0.6769 & 110.005 & N/A & N/A & N/A & 7446.5 \\
\hline & D & 103.271 & 159.19 & 0.1677 & 0.3621 & 72.696 & 4003.93 & 3282.05 & 19.744 & 7305.73 \\
\hline & $\mathbf{T}$ & 102.748 & 158.868 & 0.1683 & 0.3607 & 72.955 & 4004.06 & 3305.50 & 19.883 & 7329.45 \\
\hline & MT & 102.380 & 158.640 & 0.1687 & 0.3640 & 73.138 & N/A & 3322.04 & N/A & 7326.25 \\
\hline & MR & N/A & 113.781 & 0.2516 & 0.0688 & 109.050 & N/A & N/A & 10.549 & 7395.87 \\
\hline
\end{tabular}

8. In terms of environmental issues, model MT is better than other models because it has the most value of return rate. Specifically, the cooperation between the manufacturer and the third party could increase return rate.

The efficiency of proposed contract is presented in Table 3. As illustrated in Table 3, the equilibrium results of decision variables and total utility of chain under the coordination contract are the same as centralized CLSC in all cases; and since, according to the contract the utility of the manufacturer, the retailer and the third party are no less than their utility in decentralized model $\mathrm{D}$, the designed contract can effectively coordinate the decentralized CLSC and lead to win-win outcomes. 
Table 3

Equilibrium results of different cases under coordination contract

\begin{tabular}{rcccccccc}
\hline & $p^{*}$ & $e^{*}$ & $\tau^{*}$ & $D^{*}$ & $U_{C}{ }^{*}$ & $F_{1}^{*}>$ & $F_{2}^{*}>$ & $F_{1}^{*}+F_{2}^{*}<$ \\
\hline Case 1 & 112.588 & 0.2538 & 0.6769 & 110.005 & 7446.5 & 92.51 & 2555.82 & 2874.27 \\
Case 2 & 112.570 & 0.1269 & 0.6768 & 109.981 & 7444.9 & 92.47 & 2553.91 & 2872.08 \\
Case 3 & 113.219 & 0.2526 & 0.3369 & 109.5 & 7412.3 & 45.98 & 2559.57 & 2817.64 \\
Case 4 & 112.747 & 0.5934 & 0.6782 & 110.217 & 7460.9 & 92.84 & 2572.83 & 2893.86 \\
Case 5 & 112.588 & 0.2538 & 0.6769 & 110.005 & 7446.5 & 92.42 & 2555.85 & 2874.36 \\
Case 6 & 112.588 & 0.2538 & 0.6769 & 110.005 & 7446.5 & 88.48 & 3285.27 & 3514.54 \\
\hline
\end{tabular}

\section{Summary and conclusion}

This paper has developed a three-echelon CLSC with risk-averse players under demand uncertainty to study the effects of the players' risk aversion on the pricing, sales effort and collection rate decisions. By considering four different game decision scenarios, the equilibrium results for optimal wholesale price, optimal retail price, optimal sales effort, and optimal collection rate are derived. By comparing optimal results under different scenarios, the influence of various decision-making structures on optimal decisions and profits of CLSC has been analyzed using a numerical approach to conduct some managerial analyses. The best channel structure from the viewpoint of the CLSC and consumers is investigated. Then, we have proposed practical and novel channel coordination scheme for the CLSC with a price and sales effort dependent demand with risk-averse players. According to the results, the third party-led model has better performance than manufacturer-led model. The cooperation mode of manufacturer and retailer is beneficial for the whole chain and customers and the cooperation mode of manufacturer and third party is the most effective model to collect the used-product. Also, the results show that the proposed contract not only effectively coordinates the decentralized CLSC, but also it is advantageous from the customers and the environmental viewpoints.

For future research, the CLSC with many manufacturers, many retailers and many third parties can be considered. Also, the CLSC with information asymmetry can be studied, such as asymmetry in demand and cost information.

\section{Conflicts of Interest}

The authors declared that 'Conflicts of interest: none'

\section{References}

Aydin, R., Kwong, C. K., \& Ji, P. (2016). Coordination of the closed-loop supply chain for product line design with consideration of remanufactured products. Journal of Cleaner Production, 114, 286298.

Cachon, G. P. (2003). Supply chain coordination with contracts. Handbooks in operations research and management science, 11, 227-339.

Chen, J. M., \& Chang, C. I. (2014). Coordinating a closed-loop supply chain using a bargaining power approach. International Journal of Systems Science: Operations \& Logistics, 1(2), 69-83.

Chen, Y., Tang, X., \& Xiao, Q. (2011). Revenue-and-expense sharing contract for closed-loop supply chain coordination in multiple retail markets. Journal of Southwest Jiaotong University, 2, 029.

Chen, C. K., Weng, T. C., \& Lo, C. C. (2016). Optimal replenishment quantity for new products and return rate of used products for a retailer. Applied Mathematical Modelling, 40(23-24), 9754-9766.

Choi, T. M., Li, Y., \& Xu, L. (2013). Channel leadership, performance and coordination in closed loop supply chains. International Journal of Production Economics, 146(1), 371-380.

De Giovanni, P. (2014). Environmental collaboration in a closed-loop supply chain with a reverse revenue sharing contract. Annals of Operations Research, 220(1), 135-157. 
De Giovanni, P., Reddy, P. V., \& Zaccour, G. (2016). Incentive strategies for an optimal recovery program in a closed-loop supply chain. European Journal of Operational Research, 249(2), 605617.

Dhull, S., \& Narwal, M. (2016). Drivers and barriers in green supply chain management adaptation: A state-of-art review. Uncertain Supply Chain Management, 4(1), 61-76.

Fleischmann, M., Bloemhof-Ruwaard, J. M., Dekker, R., Van der Laan, E., Van Nunen, J. A., \& Van Wassenhove, L. N. (1997). Quantitative models for reverse logistics: A review. European journal of operational research, 103(1), 1-17.

Gao, J., Han, H., Hou, L., \& Wang, H. (2016). Pricing and effort decisions in a closed-loop supply chain under different channel power structures. Journal of Cleaner Production, 112, 2043-2057.

Govindan, K., \& Popiuc, M. N. (2014). Reverse supply chain coordination by revenue sharing contract: A case for the personal computers industry. European Journal of Operational Research, 233(2), 326-336.

Govindan, K., Popiuc, M. N., \& Diabat, A. (2013). Overview of coordination contracts within forward and reverse supply chains. Journal of Cleaner Production, 47, 319-334.

Govindan, K., \& Soleimani, H. (2017). A review of reverse logistics and closed-loop supply chains: a Journal of Cleaner Production focus. Journal of Cleaner Production, 142, 371-384.

Guide, V. D. R., \& Wassenhove, L. N. (2006). Closed-loop supply chains: an introduction to the feature issue (part 1). Production and Operations Management, 15(3), 345-350.

Guo, Y., \& Ma, J. (2013). Research on game model and complexity of retailer collecting and selling in closed-loop supply chain. Applied Mathematical Modelling, 37(7), 5047-5058.

Hafezalkotob, A., Makui, A., \& Sadjadi, S. J. (2011). Strategic and tactical design of competing decentralized supply chain networks with risk-averse participants for markets with uncertain demand. Mathematical Problems in Engineering, 2011.

Heydari, J., Govindan, K., \& Jafari, A. (2017). Reverse and closed loop supply chain coordination by considering government role. Transportation Research Part D: Transport and Environment, 52, 379-398.

Hong, X., Xu, L., Du, P., \& Wang, W. (2015). Joint advertising, pricing and collection decisions in a closed-loop supply chain. International Journal of Production Economics, 167, 12-22.

Huang, M., Song, M., Lee, L. H., \& Ching, W. K. (2013). Analysis for strategy of closed-loop supply chain with dual recycling channel. International Journal of Production Economics, 144(2), 510520.

Huang, M., Yi, P., Guo, L., \& Shi, T. (2015). Multi-dimensional Reverse Channel Decision under Different Collection Strategies. IFAC-PapersOnLine, 48(3), 357-361.

Jawla, P., \& Singh, S. (2016). A reverse logistic inventory model for imperfect production process with preservation technology investment under learning and inflationary environment. Uncertain Supply Chain Management, 4(2), 107-122.

Karakayali, I., Emir-Farinas, H., \& Akcali, E. (2007). An analysis of decentralized collection and processing of end-of-life products. Journal of Operations Management, 25(6), 1161-1183.

Ma, J., \& Wang, H. (2014). Complexity analysis of dynamic noncooperative game models for closedloop supply chain with product recovery. Applied Mathematical Modelling, 38(23), 5562-5572.

Mahmoudzadeh, M., Sadjadi, S. J., \& Mansour, S. (2013). Robust optimal dynamic production/pricing policies in a closed-loop system. Applied Mathematical Modelling, 37(16-17), 8141-8161.

Masoudipour, E., Amirian, H., \& Sahraeian, R. (2017). A novel closed-loop supply chain based on the quality of returned products. Journal of cleaner production, 151, 344-355.

Modak, N. M., Modak, N., Panda, S., \& Sana, S. S. (2018). Analyzing structure of two-echelon closedloop supply chain for pricing, quality and recycling management. Journal of Cleaner Production, 171, 512-528.

Prahinski, C., \& Kocabasoglu, C. (2006). Empirical research opportunities in reverse supply chains. Omega, 34(6), 519-532.

Ray, A., \& Mondal, S. (2016). Selection of buyback price for OEM for efficient spare parts management in remanufacturing business. Uncertain Supply Chain Management, 4(3), 233-248. 
Rubio, S., \& Corominas, A. (2008). Optimal manufacturing-remanufacturing policies in a lean production environment. Computers \& Industrial Engineering, 55(1), 234-242.

Savaskan, R. C., Bhattacharya, S., \& Van Wassenhove, L. N. (2004). Closed-loop supply chain models with product remanufacturing. Management science, 50(2), 239-252.

Savaskan, R. C., \& Van Wassenhove, L. N. (2006). Reverse channel design: the case of competing retailers. Management science, 52(1), 1-14.

Shang, W., \& Yang, L. (2015). Contract negotiation and risk preferences in dual-channel supply chain coordination. International Journal of Production Research, 53(16), 4837-4856.

Tang, X., Chen, Y., Qin, F., \& Xiao, Q. (2010). Revenue-and-expense sharing contract of closed-loop supply chain with two markets. In ICLEM 2010: Logistics For Sustained Economic Development: Infrastructure, Information, Integration (pp. 4343-4349).

Wang, W., Zhang, Y., Li, Y., Zhao, X., \& Cheng, M. (2017). Closed-loop supply chains under rewardpenalty mechanism: Retailer collection and asymmetric information. Journal of cleaner production, 142, 3938-3955.

Wei, J., Govindan, K., Li, Y., \& Zhao, J. (2015). Pricing and collecting decisions in a closed-loop supply chain with symmetric and asymmetric information. Computers \& Operations Research, 54, 257-265.

Wei, J., \& Zhao, J. (2013). Reverse channel decisions for a fuzzy closed-loop supply chain. Applied Mathematical Modelling, 37(3), 1502-1513.

Weraikat, D., Zanjani, M. K., \& Lehoux, N. (2016). Coordinating a green reverse supply chain in pharmaceutical sector by negotiation. Computers \& Industrial Engineering, 93, 67-77.

Whalley, A. E. (2011). Optimal R\&D investment for a risk-averse entrepreneur. Journal of Economic Dynamics and Control, 35(4), 413-429.

Wu, C. H. (2012). Price and service competition between new and remanufactured products in a twoechelon supply chain. International Journal of Production Economics, 140(1), 496-507.

Xie, G., Yue, W., Wang, S., \& Lai, K. K. (2011). Quality investment and price decision in a risk-averse supply chain. European Journal of Operational Research, 214(2), 403-410.

Xiao, T., \& Yang, D. (2008). Price and service competition of supply chains with risk-averse retailers under demand uncertainty. International Journal of Production Economics, 114(1), 187-200.

Xiao, T., Choi, T. M., Yang, D., \& Cheng, T. C. E. (2012). Service commitment strategy and pricing decisions in retail supply chains with risk-averse players. Service Science, 4(3), 236-252.

Xiao, T., \& Xu, T. (2014). Pricing and product line strategy in a supply chain with risk-averse players. International Journal of Production Economics, 156, 305-315.

Yan, B., Jin, Z., Liu, Y., \& Yang, J. (2018). Decision on risk-averse dual-channel supply chain under demand disruption. Communications in Nonlinear Science and Numerical Simulation, 55, 206-224.

Zhang, C. T., \& Ren, M. L. (2016). Closed-loop supply chain coordination strategy for the remanufacture of patented products under competitive demand. Applied Mathematical Modelling, 40(13-14), 6243-6255.

Zhou, Y. W., Li, J., \& Zhong, Y. (2018). Cooperative advertising and ordering policies in a two-echelon supply chain with risk-averse agents. Omega, 75, 97-117.

Zu-Jun, M., Zhang, N., Dai, Y., \& Hu, S. (2016). Managing channel profits of different cooperative models in closed-loop supply chains. Omega, 59, 251-262. 


\section{Appendix A}

In this appendix, the proof that the utility functions of members are concave in the decision variables is presented.

Proof of Proposition 1. Hessian matrix of $u_{C}$ is

$$
H=\left[\begin{array}{ccc}
-\left(2 b+\lambda_{m} \sigma^{2}\right) & L & -\left(b+\lambda_{m} \sigma^{2}\right) \Delta \\
L & -\eta & L \Delta \\
-\left(b+\lambda_{m} \sigma^{2}\right) \Delta & L \Delta & -2 \lambda-\lambda_{m} \sigma^{2} \Delta^{2}
\end{array}\right]
$$

The total utility function of chain is concave in $p, e$ and $\tau$ if and only if Hessian matrix $H$ is negative definite. Due to $b, \lambda_{m}, \sigma^{2}>0$, if $\eta\left(2 b+\lambda_{m} \sigma^{2}\right)-\mathrm{L}^{2}>0$ and $4 b \eta \lambda+2 L^{2} \Delta^{2} \lambda_{m} \sigma^{2}>2 \eta \lambda_{m} \sigma^{2}\left(\lambda+\Delta^{2} \lambda_{m} \sigma^{2}\right)+2 L^{2} \lambda+b^{2} \Delta^{2} \eta$, the Hessian matrix of $u_{C}$ is negative definite. The proof of Proposition 1 is completed.

Proof of Proposition 2. Hessian matrix of $u_{R}$ is

$$
H=\left[\begin{array}{cc}
-\left(2 b+\lambda_{R} \sigma^{2}\right) & L \\
L & -\eta
\end{array}\right]
$$

The retailer's utility function is concave in $p$ and $e$ if and only if Hessian matrix $H$ is negative definite. Due to $b, \lambda_{R}, \sigma^{2}>0$, if $\eta\left(2 b+\lambda_{R} \sigma^{2}\right)-L^{2}>0$, the Hessian matrix $H$ is negative definite. The proof of Proposition 2 is completed.

Proof of Proposition 3. Taking the second-order partial derivatives of $u_{T}$ with respect to $\tau$, we obtain $\frac{\partial^{2} u_{T}}{\partial \tau^{2}}=-2 \lambda-\lambda_{T} \sigma^{2} f^{2}$.

Due to $\lambda \geq 0$ and $\lambda_{T} \geq 0$, the second derivative is negative. So, the third party's utility is concave in $\tau$. The proof of Proposition 3 is completed.

Proof of Proposition 4. Taking the second-order partial derivatives of $u_{M}$ with respect to $w$, we obtain $\frac{\partial^{2} u_{M}}{\partial w^{2}}=-b\left(A_{1} B+E\right)\left(2 k B-\lambda_{m} \sigma^{2}\left(A_{1} B+E\right)\right)$.

If $b\left(A_{1} B+E\right)\left(2 k B-\lambda_{m} \sigma^{2}\left(A_{1} B+E\right)\right)>0$, the second derivative is negative. So, the manufacturer's utility function is concave in $w$. The proof of Proposition 4 is completed.

Proof of Proposition 5. Hessian matrix of $u_{M T}$ is

$$
H=\left[\begin{array}{cc}
b\left(2 k-A_{1} \lambda_{m} \sigma^{2}\right) & b \Delta\left(k-A_{1} \lambda_{m} \sigma^{2}\right) \\
\left.b \Delta k-b A_{1} \lambda_{m} \sigma^{2} \Delta\right) & -b A_{1}\left(2 \lambda+\lambda_{m} \sigma^{2} \Delta^{2}\right)
\end{array}\right]
$$

The total utility function of manufacturer and third party is concave in $w$ and $\tau$ if and only if Hessian matrix $H$ is negative definite. If $2 b^{2} A_{1} \lambda\left(A_{1} \lambda_{m} \sigma^{2}-2 k\right)-b^{2} k^{2} \Delta^{2}>0$ and $A_{1} \lambda_{m} \sigma^{2}>2 k$, the Hessian matrix of $u_{M T}$ is negative definite. The proof of Proposition 5 is completed.

Proof of Proposition 6. Taking the second-order partial derivatives of $u_{M}$ with respect to $w$, we obtain $\frac{\partial^{2} u_{M}}{\partial w^{2}}=-b\left(A_{1} \lambda_{m} \sigma^{2}-2 k\right)$ 
If $b\left(A_{1} \lambda_{m} \sigma^{2}-2 k\right)>0$, the second derivative is negative. So, the manufacturer's utility function is concave in $w$

Proof of Proposition 7. Taking the second-order partial derivatives of $u_{T}$ with respect to $\tau$, we obtain $\frac{\partial^{2} u_{T}}{\partial \tau^{2}}=-2 b E\left(k-A_{1} \lambda_{m} \sigma^{2}\right)-b A_{1} \mathrm{~B}\left(A_{1} \lambda_{m} \sigma^{2}-2 k\right)$.

If $2 b E\left(k-A_{1} \lambda_{m} \sigma^{2}\right)+b A_{1} \mathrm{~B}\left(A_{1} \lambda_{m} \sigma^{2}-2 k\right)>0$, the second derivative is negative. So, the third party's utility function is concave in $\tau$.

Proof of Proposition 8. Hessian matrix of $u_{M R}$ is $H=\left[\begin{array}{cc}-\left(2 b+\lambda_{m} \sigma^{2}\right) & L \\ L & -\eta\end{array}\right]$

The total utility function of manufacturer and retailer is concave in $p$ and $e$ if and only if Hessian matrix $H$ is negative definite. Due to $b, \lambda_{m}, \sigma^{2}>0$, if $\eta\left(2 b+\lambda_{m} \sigma^{2}\right)-L^{2}>0$, the Hessian matrix of $u_{M R}$ is negative definite. The proof of Proposition 8 is completed.

Proof of Proposition 9. Taking the second-order partial derivatives of $u_{T}$ with respect to $\tau$, we obtain $\frac{\partial^{2} u_{T}}{\partial \tau^{2}}=2 f(\Delta-f) \eta b\left(b+\lambda_{m} \sigma^{2}\right)-A_{4} B$

If $A_{4} B-2 f(\Delta-f) \eta b\left(b+\lambda_{m} \sigma^{2}\right)>0$, the second derivative is negative. So, the third party's utility function is concave in $\tau$.

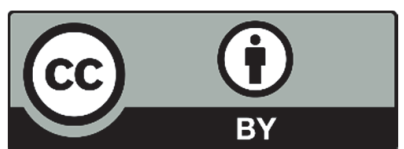

(C) 2018 by the authors; licensee Growing Science, Canada. This is an open access article distributed under the terms and conditions of the Creative Commons Attribution (CC-BY) license (http://creativecommons.org/licenses/by/4.0/). 